\title{
Hospital pharmacists understanding of available health literacy assessment tools and their perceived barriers for incorporation in patient education - a survey study
}

Sara Chan ${ }^{1}$, Sean P. Spina ${ }^{1,2}$, Dalyce M. Zuk ${ }^{3}$ and Karen Dahri ${ }^{1,4^{*}}$ (D)

\begin{abstract}
Background: Patients with low health literacy experience difficulty in understanding their medications leading to worse health outcomes. Pharmacists need to use formal assessment tools to be able to identify these patients, so they can better tailor their patient education. The objective of the study was to characterize hospital pharmacists understanding of health literacy and their use of screening and counselling strategies before and after completion of an educational module and to identify barriers that hospital pharmacists perceive to exist that prevent them from using health literacy tools.
\end{abstract}

Methods: Pharmacists in three health authorities were administered a pre-survey and then given access to an online 11 min educational video. The post-survey was distributed 1 month later. Descriptive statistics were used to quantify survey responses with comparisons made between pre and post responses. The main outcome measure was pharmacists' understanding of health literacy and their current practice related to health literacy.

Results: There were 131 respondents for the pre-survey and 39 for the post-survey. In the pre-module survey, 84\% of pharmacists felt they understood what health literacy was, but only $53 \%$ currently assessed patients for their health literacy status and $40 \%$ were aware of what strategies to use in low health literacy patients. Lack of time (74\%) was the biggest barrier in assessing patients' health literacy. In the post-module survey, $87 \%$ felt they understood what health literacy was and $64 \%$ incorporated health literacy status evaluation into their clinical practice. The educational module was helpful to the clinical practice of $74 \%$ of respondents.

Conclusion: As health literacy can affect a patient's ability to adhere to their medications it is important for pharmacists to assess this in their patients. While pharmacists self-reported a high degree of understanding of health literacy, they are not regularly assessing their patients' health literacy status and are unaware of what strategies to use for low literacy patients.

Keywords: Health literacy, Pharmacy practice, Medication adherence

\footnotetext{
* Correspondence: Karen.Dahri@vch.ca

${ }^{1}$ Faculty of Pharmaceutical Sciences, University of British Columbia, 2405 Wesbrook Mall, Vancouver, BC V6T 1Z3, Canada

${ }^{4}$ Vancouver General Hospital, Vancouver Coastal Health, 855 West 12th Avenue, Vancouver, BC V5Z 1M9, Canada

Full list of author information is available at the end of the article
} 


\section{Background}

While literacy refers to an individual's ability to read and write, the World Health Organization (WHO) defines health literacy to be "the cognitive and social skills which determine the motivation and ability of individuals to gain access to, understand, and use information in ways which promote and maintain good health" [1]. According to $\mathrm{WHO}$, an individual with low health literacy refers to a person who may experience challenges in managing their own health effectively, accessing health services and understanding available health information, thus decreasing the likelihood of making informed health decisions [1]. Approximately $60 \%$ of adults and $88 \%$ of elderly individuals in Canada have low health literacy [2]. Low health literacy has been strongly associated with many negative health outcomes such as greater emergency care use, increased rates of hospitalization, lower use of preventative health services such as mammography screening and yearly flu vaccine and increased risk of mortality [3, 4]. Patients have a decreased ability to demonstrate appropriate selfadministration of medications and may misinterpret instructions and have poor adherence to their medication regimens [5, 6]. Previous studies of patients with low health literacy found incorrect medication dosing or administration errors in over $28 \%$ of the subjects surveyed with the most frequent mistakes pertaining to dosage measurement and frequency of dosage administration [6]. Rates of low health literacy tend to be higher in individuals who possess at least one of the following demographic characteristics: elderly, ethnic minorities, individuals who have not completed high school, adults who speak a language other than English prior to entering school, and people living in poverty $[3,5]$.

While these demographic characteristics have been reported, past literature has shown us that it is difficult to accurately identify patients with low health literacy without using standardized assessment methods [7]. In a cross-sectional study of 182 subjects, without formally assessing for health literacy status, medical residents were only able to identify low health literacy in $10 \%$ of the patients, despite $32 \%$ of patients testing positive for low health literacy [8]. This illustrates that the use of a formal assessment tool can greatly help clinicians in accurately identifying individuals with low health literacy $[8,9]$.

Currently, the most common and widespread screening tools for health literacy are the Rapid Estimate of Adult Literacy in Medicine (REALM) and the Test of Functional Health Literacy in Adults (TOFHLA) [10, 11]. There are shortened and revised versions of each to help promote temporal efficiency in administration of the tools $[10,11]$. However, there have been substantial differences noted in gender and ethnicity, despite stratification for education $[10,11]$. There has been an increase in the development of new screening tools, particularly instruments that can be administered in under 15 min; however, many of them have not been extensively studied and tested [7, 12-16]. In terms of multiitem screening tools, the Newest Vital Sign (NVS) has been tested multiple times [17-21]. It has shown to be a reliable and accurate measure of health literacy $[17,22$, 23]. It takes approximately $3 \mathrm{~min}$ to administer [24]. Furthermore, studies reported that patients generally felt satisfied with the administration of the NVS and they did not feel shame for being screened with the tool [25, 26]. However, it does appear to have limited practical use in the elderly African-American adult population [18]. In terms of single-item screening tools, the question of "how confident are you in filling medical forms by yourself?" has shown to be accurate in detecting limited and marginal health literacy [7, 12, 13, 27]. The question can be answered with one of the following options: to a great extent, somewhat, very little, and not at all $[7,12,13,27]$.

Given the variety of the assessment tools available, pharmacists could benefit from learning at least one of these assessment tools in order to more effectively identify patients with low health literacy. Unfortunately, uptake amongst community pharmacists has been low. Studies conducted in community pharmacies have shown that only $7 \%$ of pharmacies reported that they attempted to identify patients with health literacy needs [28]. If health professional driven assessment is not done it is unlikely that patients will self-declare their health literacy needs [29]. Many patients with low health literacy often feel a sense of shame which may discourage them from revealing their health literacy status [29]. One study showed that $67.2 \%$ of patients with low health literacy had never told their spouses and $53.4 \%$ had never told their children of their difficulties in reading [29].

Pharmacists can utilize different strategies to tailor patient education for individuals with low health literacy. Communication techniques and patient counselling strategies exist to help support the learning of patients with inadequate health literacy [3, 8, 30-33]. However, in order to utilize these strategies, pharmacists need to be able to effectively identify these patients. Hence, the need for pharmacists to integrate the use of health literacy assessment tools into their practice. It is unclear whether hospital-based pharmacists currently assess patients' health literacy or utilize health literacy screening tools. The objective of this study is to survey pharmacists in hospital-based practices to characterise their understanding of health literacy and their use of screening and counselling strategies prior to and following the completion of an educational module regarding health 
literacy. In addition, to identify barriers that pharmacists perceive to exist that prevent them from using health literacy tools.

\section{Methods}

Pharmacists in three health authorities [Lower Mainland Pharmacy Services (LMPS), Vancouver Island Health Authority (VIHA), Alberta Health Services (AHS)] were recruited to participate in the study. Ethics approval was obtained from the University of British Columbia (UBC) Clinical Research Ethics Board. All participants gave their informed consent.

A pre and post survey was developed and was based on a comprehensive search of the literature $[9,34]$. The pre-survey questions were focused on the pharmacists understanding of health literacy, whether they currently employ any strategies to assess and counsel patients, and identification of the barriers that prevent them from assessing patients' health literacy. The post-survey assessed the pharmacist's perspective on the impact of the health literacy module on their practice and whether it influenced their use of screening tools and counselling strategies. It also explored methods to encourage increased use of such strategies. Both sets of survey questions were reviewed by a small group of practicing Canadian pharmacists to ensure face and content validity. The survey questions were not statistically validated. All survey questions were in English only. Surveys were created in FluidSurveys@ which at the time of this study was the designated survey tool available through UBC and was in compliance with the privacy rules in British Columbia with all data being stored and backed up in Canada.

The educational module itself was an 11-min educational video titled "Reading Into the Health Literacy of Our Patients". The investigators created it for the purpose of the study and its content was based on an extensive review of the literature $[3-8,17,18,22,25-27,30-$ $33,35,36]$. It focused on educating the viewer on the definition of health literacy, how to assess patients that had low health literacy and the strategies that could be used when counselling patients with low health literacy. Once participants completed the pre-module survey they were given access to the video link in Vimeo@. The video link was also made available to staff outside the context of the study.

\section{Survey administration}

The initial pre-module survey was distributed via group e-mail lists to pharmacists within each of the three health authorities. A reminder e-mail was sent 1 week later. After completion of the initial survey, participants were asked for permission for the study investigators to contact them 1 month later with the post-module survey. The survey was estimated to take approximately $5 \mathrm{~min}$ to complete. All of the survey invitations and reminders contained consent information. Consent was implied by responding to the survey. Responses to the survey as a whole and to the individual survey questions was entirely voluntary.

Pharmacists were included in the study if they were involved in any direct patient care activities. Questions were embedded into the start of the survey to screen for this inclusion criteria. An incentive of a draw for one of four $\$ 25$ coffee gift cards was offered to all potential participants. Funding for the study was from the unrestricted research start-up grant of the primary investigator (KD).

Data analysis consisted of simple descriptive statistics which included total counts, percentages, averages, and standard deviations. Comparisons of responses before and after completion of the educational module was planned. Qualitative analysis of open-ended responses was also done.

\section{Results}

One hundred and thirty-one pharmacists completed the pre-survey and thirty-nine completed the post-survey. Table 1 outlines the baseline demographics of the presurvey cohort. The overall response rate for the presurvey was $6 \%$ and for the post-survey was $29 \%(38 / 131$ pre-survey respondents).

Prior to completing the educational module, $84 \%$ of the participants felt they understood health literacy with 53\% currently assessing patients for health literacy in their practice (Table 2). The most commonly used strategies of assessing a patient's health literacy were those that relied on subjective observations (Table 3). Patient's verbal communication (76\%), demonstrated understanding of medications (76\%) and personal intuition (73\%) were the most common assessment methods that pharmacists relied on. During counselling sessions,

Table 1 Baseline Characteristics for Participants in Each Health Authority

\begin{tabular}{lllll}
\hline $\begin{array}{l}\text { Health } \\
\text { Authority }\end{array}$ & $\begin{array}{l}\text { Number of } \\
\text { Participants } \\
\text { Number) }\end{array}$ & $\begin{array}{l}\text { Total } \\
\text { Number of } \\
\text { Pharmacists } \\
\text { (Number) }\end{array}$ & $\begin{array}{l}\text { Overall } \\
\text { Response }\end{array}$ & $\begin{array}{l}\text { Rate per } \\
\text { Health } \\
\text { Authority } \\
\text { Experience (Mean, } \\
\text { SD) }\end{array}$ \\
\hline LMPS & 20 & 534 & 4 & $12.8,9.7$ \\
VIHA & 15 & 186 & 8 & $\begin{array}{l}17.5,11.8 \\
\text { Alberta }\end{array} 96$ \\
& 1461 & 7 & $\begin{array}{l}8.5,5.3 \text { [Note: } 33 \\
\text { pharmacists } \\
\text { reported }>20 \text { years } \\
\text { and were not } \\
\text { included in } \\
\text { calculation of } \\
\text { mean] }\end{array}$ \\
\hline
\end{tabular}


Table 2 Pre-module Survey Questions and Responses - Total (Percent)

\begin{tabular}{llll}
\hline & Yes & No & Total \\
\hline I feel I understand what health literacy is & 109 & 21 & 130 \\
& $(84)$ & $(16)$ & \\
I currently assess patients for their health literacy & 69 & 62 & 131 \\
status as part of my clinical practice. & $(53)$ & $(47)$ & \\
I am aware of what strategies to use when & 53 & 77 & 130 \\
interacting with patients with inadequate health & $(41)$ & $(59)$ & \\
literacy. & & & \\
I am comfortable when counselling patients with & 88 & 42 & 130 \\
inadequate health literacy. & $(68)$ & $(32)$ & \\
$\begin{array}{l}\text { Do you use any particular strategies for counselling } \\
\text { when interacting with patients with inadequate }\end{array}$ & $(63)$ & 46 & 125 \\
versus adequate health literacy? & & & \\
\hline
\end{tabular}

pharmacists would most often present essential information by itself and use simpler language (81\%) when counselling patients with inadequate health literacy. Time constraints were the most common barrier that prevented practitioners from assessing their patients and using counselling strategies.

Of the 38 pharmacists that completed the post-survey, $74 \%$ felt that completing the educational module on health literacy was helpful to their clinical practice (Table 4). Time constraints continued to be the biggest challenge to implementing health literacy assessment (72\%) and counselling strategies (67\%) into their practice (Table 5).

Comparisons between pre and post module survey responses to the questions regarding whether participants understand what health literacy is and if they currently assess patients for their health literacy status were not statistically significantly different.

Open-ended responses were also incorporated into the survey design. Qualitative analysis of these responses with categorization of themes found that many of these responses would fit into an existing response. For example, an open-ended response to the pre-survey question of counselling strategies used for patients with health literacy was "Highlighting and writing information in simpler words on teaching sheets." Which would fit into the existing option of "Ensuring that printed materials area easy to read for patients".

\section{Discussion}

Our study assessed the pharmacists baseline knowledge of health literacy; their use of health literacy assessment tools and counselling strategies; and whether an educational video intervention had an impact on their practice. In addition, barriers to the implementation of health literacy patient assessment and counselling strategies that prevent pharmacists from integrating these interventions into their clinical practice were also identified. While pharmacists self-reported a high rate of understanding of health literacy, just over half of the study population indicated that they currently assessed patients for health literacy and only $41 \%$ were aware of what strategies to use with most relying on just subjective patient observation.

Interestingly while survey respondents were not aware of the strategies to use, $63 \%$ indicated they use specific strategies when counselling patients with low health literacy. The majority of the study population seemed to use strategies such as presenting essential information first, asking patients to demonstrate what has been taught and encouraging the presence of a family member. While these strategies have been shown to improve patient comprehension, other standardized communication techniques such as the Indian Health Service Model, the Teach-back method, and the Ask-Me-3 method have been shown to better promote understanding in patients with inadequate health literacy $[8,30,31$, 33]. Multiple resources also exist to provide guidance on patient interaction and also on how to structure teaching information all of which would be valuable to pharmacists to further advance their skills [3, 31].

Time continues to be a barrier for using an assessment tool to screen for patient's health literacy and in deters pharmacists from using the available counselling strategies as found again in our study. While time constraints are consistently reported as a barrier Welch et al. evaluated the implementation of the Newest Vital Sign (NVS) instrument in a primary care clinic and found that it took $30 \mathrm{~s}$ to hand out the forms and instruct patients on how to fill them out [24]. It took an additional 2 min to score and enter the results into the patient's electronic medical record [24]. Overall, tests such as REALM, STOFHLA, and METER take on average 2-12 min and are more accurate than using practitioner selfassessment [13]. Patients can also be simply asked questions as a single-item screening tool [7, 12, 13, 27]. For example, the question of "how confident are you in filling medical forms by yourself?" with patients being given the following options as answers to the question: to a great extent, somewhat, very little, and not at all has shown to be accurate in detecting limited and marginal health literacy $[7,12,13,27]$. Or pharmacists can adopt Health Literacy Universal Precautions as recommended by the Agency for Healthcare Research and Quality where strategies used to educate low health literacy patients are done for everyone [37].

Since the response rate for the post-survey was considerably lower than the pre-survey, we were not able to assess whether the educational intervention had an impact on practice. Other studies that have looked at factors that influence the adoption and implementation of health literacy tools in community pharmacy settings have identified a number of barriers that prevent 
Table 3 Pre-Module Survey Questions and Responses ( $N=131)$

\begin{tabular}{|c|c|c|c|}
\hline Question & Responses & Count & Percent \\
\hline \multirow[t]{9}{*}{ How do you currently assess patients for health literacy? } & Personal intuition & 95 & 73 \\
\hline & Patient's level of formal education attained & 37 & 28 \\
\hline & Patient's verbal communication & 100 & 76 \\
\hline & Patient's written communication skills, if observable & 35 & 27 \\
\hline & Patient's demonstrated use of medications, if observable & 73 & 56 \\
\hline & $\begin{array}{l}\text { Patient's demonstrated understanding of medications, if } \\
\text { observable }\end{array}$ & 100 & 76 \\
\hline & Formal health literacy assessment tool & 2 & 2 \\
\hline & I do not assess patients for health literacy & 14 & 11 \\
\hline & Other & 4 & 3 \\
\hline \multirow[t]{8}{*}{$\begin{array}{l}\text { Which of the following strategies do you use when counselling patients } \\
\text { with inadequate health literacy? }\end{array}$} & $\begin{array}{l}\text { Asking the patient to demonstrate what you just taught } \\
\text { them and to ask questions }\end{array}$ & 100 & 76 \\
\hline & $\begin{array}{l}\text { Engaging in frequent short appointments, instead of one } \\
\text { long appointment }\end{array}$ & 40 & 30 \\
\hline & $\begin{array}{l}\text { Presenting essential information by itself or first, and } \\
\text { using simpler language }\end{array}$ & 106 & 81 \\
\hline & Encouraging the presence of a family member & 93 & 71 \\
\hline & $\begin{array}{l}\text { Ensuring that printed materials are easy to read for } \\
\text { patients }\end{array}$ & 78 & 60 \\
\hline & $\begin{array}{l}\text { Using more than one source of media in teaching (for } \\
\text { example diagrams and video) }\end{array}$ & 28 & 21 \\
\hline & $\begin{array}{l}\text { I do not use any particular strategies when counseling } \\
\text { patients with inadequate health literacy }\end{array}$ & 8 & 6 \\
\hline & Other & 9 & 7 \\
\hline \multirow{7}{*}{$\begin{array}{l}\text { Of the following, which barriers do you feel may deter you from } \\
\text { assessing patients for their health literacy? }\end{array}$} & Lack of financial incentives & 3 & 2 \\
\hline & Time constraints & 97 & 74 \\
\hline & Being liable for results of the assessment & 9 & 7 \\
\hline & $\begin{array}{l}\text { Patient's expectations of your clinical practice and your } \\
\text { own expectations of your routine in your practice }\end{array}$ & 34 & 26 \\
\hline & Opinions of your practice leader(s) & 2 & 2 \\
\hline & Feeling insufficiently trained to use assessment tools & 80 & 61 \\
\hline & Other & 3 & 2 \\
\hline \multirow{7}{*}{$\begin{array}{l}\text { Of the following, which barriers do you feel may deter you from using } \\
\text { the counselling strategies available? }\end{array}$} & Lack of financial incentives & 5 & 4 \\
\hline & Time constraints & 106 & 81 \\
\hline & Being liable for results of the assessment & 19 & 15 \\
\hline & $\begin{array}{l}\text { Patient's expectations of your clinical practice and your } \\
\text { own expectations of your routine in your practice }\end{array}$ & 19 & 15 \\
\hline & Opinions of your practice leader(s) & 4 & 3 \\
\hline & Feeling insufficiently trained to use assessment tools & 56 & 43 \\
\hline & Other & 13 & 10 \\
\hline \multirow[t]{6}{*}{$\begin{array}{l}\text { Of the following, which would encourage you to use any of the } \\
\text { counselling strategies for patients with inadequate health literacy? }\end{array}$} & $\begin{array}{l}\text { Engaging in interactive small group meetings with your } \\
\text { colleagues to discuss the counselling strategies }\end{array}$ & 66 & 50 \\
\hline & E-mail reminders to use the counselling strategies & 18 & 14 \\
\hline & $\begin{array}{l}\text { Computerized decision support to use the counselling } \\
\text { strategies }\end{array}$ & 57 & 44 \\
\hline & Mass media campaign on using the counselling strategies & 19 & 15 \\
\hline & Financial incentives & 20 & 15 \\
\hline & Other & 25 & 19 \\
\hline
\end{tabular}


Table 4 Post-module Survey Questions and Responses - Total (Percent)

\begin{tabular}{|c|c|c|c|}
\hline & Yes & No & Total \\
\hline I feel I understand what health literacy is & $34(87)$ & $4(10)$ & 38 \\
\hline I currently assess patients for their health literacy status as part of my clinical practice. & $25(64)$ & $13(33)$ & 38 \\
\hline I feel I assess the health literacy status of patients more effectively & $21(54)$ & $17(44)$ & 38 \\
\hline I feel I use more counselling strategies tailored for patients with inadequate health literacy & $21(54)$ & $17(44)$ & 38 \\
\hline I feel that completing an educational module on health literacy was helpful for my clinical practice & $29(74)$ & $9(23)$ & 38 \\
\hline
\end{tabular}

implementation. Factors preventing uptake include limited support from leadership, higher prioritization of other activities, lack of qualified staff and complexity of the tool being used [38]. The second most reported barrier in our study to implementation of health literacy strategies was a feeling of being insufficiently trained to use the assessment tools. While we were not able to draw conclusions from the educational intervention that we implemented, a prior study that assessed the implementation of the Agency for Healthcare Research and Quality pharmacy health literacy assessment tool in a community pharmacy setting found that the training program had limited impact on patient and staff responses [39].

Table 5 Post-module Survey Questions and Responses $(N=38)$

Question
patients for their health literacy?

Of the following, which barriers do you feel may deter you from using the counselling strategies available?

Of the following, which would encourage you to use any of the counselling strategies for patients with inadequate health literacy?

patients for their health literacy?
There were many limitations of this study. We did not prospectively assess pharmacists understanding of health literacy; we asked them to self-report if they felt that they had an understanding. The poor response rate for the post-survey limits our ability to determine if the educational intervention had any impact on the pharmacists' practice. While we educated the pharmacists on what tools were available we did not provide any detailed training on how to use the tools. In addition, our educational intervention was limited to a short video.

\section{Conclusion}

Our study did highlight a need for organized educational interventions to pharmacists on health literacy.

\begin{tabular}{lll} 
Responses & Total & $\%$ \\
\hline Lack of financial incentives & 2 & 5 \\
Time constraints & 28 & 72 \\
Being liable for results of the assessment & 1 & 3 \\
Patient's expectations of your clinical practice and your own & 14 & 36 \\
expectations of your routine in your practice & & \\
Opinions of your practice leader(s) & 2 & 5 \\
Feeling insufficiently trained to use assessment tools & 16 & 41 \\
Other & 5 & 13 \\
Lack of financial incentives & 2 & 5 \\
Time constraints & 26 & 67 \\
Being liable for results of the assessment & 10 & 26 \\
Patient's expectations of your clinical practice and your own & 12 & 31 \\
expectations of your routine in your practice & & \\
Opinions of your practice leader(s) & 5 & 13 \\
Feeling insufficiently trained to use assessment tools & 56 & 43 \\
Other & 13 & 10 \\
Engaging in interactive small group meetings with your & 15 & 39 \\
colleagues to discuss the counselling strategies & & \\
E-mail reminders to use the counselling strategies & 11 & 28 \\
Computerized decision support to use the counselling & 14 & 36 \\
strategies & & \\
Mass media campaign on using the counselling strategies & 5 & 13 \\
Financial incentives & 6 & 15 \\
Other & 5 & 13 \\
\hline
\end{tabular}


Pharmacists may self-report a good understanding of health literacy, but they do not regularly assess their patients' health literacy status and are unaware of what strategies should be used for low literacy patients. From our survey, pharmacists indicated that they would prefer engaging in interactive small group meetings with colleagues or utilizing computerized decision support. Future research should explore which tools are most appropriate for pharmacists to use and how best to implement a practice change.

\section{Abbreviations \\ REALM: Rapid Estimate of Adult Literacy in Medicine; TOFHLA: Test of Functional Health Literacy in Adults; LMPS: Lower Mainland Pharmacy Services; VIHA: Vancouver Island Health Authority; AHS: Alberta Health Services; UBC: University of British Columbia; NVS: Newest Vital Sign}

\section{Acknowledgements \\ I certify that Cindy McMinis, who has made substantial contributions to the work reported in this manuscript but did not fulfill the authorship criteria, is named in the acknowledgement section and has provided written permission to be named. \\ This work was presented as a poster at the Canadian Society of Hospital Pharmacists Professional Practice Conference Feb 3-6 2019 in Toronto, Ontario.}

\section{Authors' contributions}

SC - contributed to the conception and design of the study; acquisition, analysis, and interpretation of the data; and the manuscript draft and its subsequent revisions. SS - contributed to the study design; acquisition and interpretation of the data and the revisions of the manuscript. DZ contributed to the study design; to the acquisition and interpretation of the data and the revisions of the manuscript. KD - contributed to the conception and design of the study; acquisition, analysis, and interpretation of the data; and the manuscript draft and its subsequent revisions. All authors have reviewed and approved the submitted version and are accountable for its contents.

\section{Funding}

The study was funded from Dr. Karen Dahri's unrestricted research start-up grant. The funding was used to pay for the $4 \$ 25$ gift cards that were offered as incentive to participate in the study.

\section{Availability of data and materials}

At the time of ethical approval and participant consent no approval was obtained for public sharing of the data sets even in a de-identified form as such the data is not available.

\section{Ethics approval and consent to participate}

Ethics approval was obtained from the University of British Columbia (UBC) Behavioral Research Ethics Board (H16-01634). All participants gave their informed consent. No written or verbal consent was provided. Consent was implied by choosing to participate in the e-mailed survey. The e-mail that was sent to potential participants contained the consent form for participants to review. They then could decide whether or not to participate in the study with participation occurring if they chose to click the link that led to the online survey. The process for consent was covered under the ethics approval.

\section{Consent for publication}

Not applicable.

\section{Competing interests}

All of the above authors have completed and submitted an ICMJE Form for Disclosure of Potential Conflicts of Interest. None of the authors have any real or potential conflicts of interest to disclose with respect to the research, authorship, and/or publication of this article.

\section{Author details}

${ }^{1}$ Faculty of Pharmaceutical Sciences, University of British Columbia, 2405 Wesbrook Mall, Vancouver, BC V6T 1Z3, Canada. ${ }^{2}$ Department of Pharmacy, Royal Jubilee Hospital, Island Health, 1952 Bay St, Victoria, BC V8R 1J8, Canada. ${ }^{3}$ Alberta Health Services, 3\#308, 3031 Hospital Drive NW, Calgary, AB T2N 2T8, Canada. ${ }^{4}$ Vancouver General Hospital, Vancouver Coastal Health, 855 West 12th Avenue, Vancouver, BC V5Z 1M9, Canada.

Received: 20 January 2020 Accepted: 29 April 2020

Published online: 11 May 2020

\section{References}

1. Health literacy and health behaviour. Geneva (SUI): World Health Organization; 2016 [cited 2016 April 26]. Available from: http://www.who. int/healthpromotion/conferences/7gchp/track2/en/.

2. Health literacy. Ottawa (ON): Public Health Agency of Canada; 2016 [cited 2016 April 26] Available from: http://www.phac-aspc.gc.ca/cd-mc/hl-Is/ index-eng.php\#tabs-2

3. Berkman ND, Sheridan S, Donahue K, Halpern D, Viera A, Crotty K, et al. Health literacy interventions and outcomes: an updated systematic review. Rockville: Agency for Healthcare Research and Quality (US); 2011. (Evidence Reports/Technology Assessments, No. 199.) Available from: https://www. ncbi.nlm.nih.gov/books/NBK82434/.

4. Andrus M, Roth M. Health literacy: a review. Pharmacotherapy. 2002;22(3): 282-302.

5. A Vision for a Health Literate Canada: Report of the Expert Panel on Health Literacy. Ottawa (ON): Canadian Public Health Association; 2016. [cited 2016 April 26] Available from: https://www.cpha.ca/vision-health-literate-canadareport-expert-panel-health-literacy.

6. Ferguson LA, Pawlak R. Health literacy: the road to improved health outcomes. JNP. 2011;7(2):123-9.

7. Chew LD, Bradley KA, Boyko EJ. Brief questions to identify patients with inadequate health literacy. Fam Med. 2004;36(8):588-94.

8. Johnson J, Moser L, Garwood C. Health literacy: a primer for pharmacists. Am J Health-Syst Pharm. 2013;70:949-55.

9. Macabasco-O'Connell A, Fry-Bowers EK. Knowledge and perceptions of health literacy among nursing professionals. J Health Commun. 2011; 16(Suppl 3):S295-307.

10. Aguirre AC, Ebrahim N, Shea J. Performance of the English and Spanish STOFHLA among publicly insured Medicaid and Medicare patients. Patient Educ Couns. 2005:56:332-9.

11. Shea J, Beers B, McDonald V, Quistberg D, Ravenell K, Asch D. Assessing health literacy in African American and Caucasian adults: disparities in rapid estimate of adult literacy in medicine (REALM) scores. Fam Med. 2004;36(8): $575-81$.

12. Wallace L, Rogers E, Roskos S, Holiday D, Weiss B. Brief report: screening items to identify patients with limited health literacy skills. J Gen Intern Med. 2006:21(8):874-7.

13. Powers B, Trinh J, Bosworth $\mathrm{H}$. Can this patient read and understand written health information? JAMA. 2010;304(1):558-65.

14. Morris N, MacLean C, Chew L, Littenberg B. The single item literacy screener: evaluation of a brief instrument to identify limited reading ability. BMC Fam Pract. 2006;7(21). https://doi.org/10.1186/1471-2296-7-21 Available from [Accessed 6 May 2016].

15. Kiechie E, Hnat A, Norman K, Viera A, DeWait D, Brice J. Comparison of brief health literacy screens in the emergency department. J Health Commun. 2015;20(5):539-45.

16. Sharp L, Ureste P, Torres L, Baily L, Gordon H, Gerber B. Time to sign: the relationship between health literacy and signature sign. Patient Educ Couns 2013:90:18-22.

17. Osborn CY, Weiss BD, Davis TC, Skripkauskas S, Rodrigue C, Bass PF, et al. Measuring adult literacy in health care: performance of the newest vital sign. Am J Health Behav. 2007:31(Suppl 1):S36-46.

18. Patel PJ, Joel S, Rovena G, Pedireddy S, Saad S, Rachmale R, et al. Testing the utility of the newest vital sign (NVS) health literacy assessment tool in older African-American patients. Patient Educ Couns. 2011;85(3):505-7.

19. Kogure $T$, Sumitani M, Suka M, Ishikawa H, Odajima T, Igarashi A, Kusama M. Validity and reliability of the Japanese version of the newest vital sign: a preliminary study. PLoS One. 2014. https://doi.org/10.1371/journal.pone. 0094582 Available from: [Accessed 3 June 2016 ]. 
20. Ragland D, Payakachat N. Health literacy in obstetric patients: a pharmacist's experience with the newest vital sign. Pharmacy. 2015;3:372-8.

21. Salgado T, Ramos S, Sobreira C, Canas R, Cunha I, Benrimoj S, FernandezLlimos F. Newest vital sign as a proxy for medication adherence in older adults. JAPHA. 2013;53(6):611-7.

22. Shah LC, West P, Bremmeyr K, Savoy-Moore RT. Health literacy instrument in family medicine: the "newest vital sign" ease of use and correlates. J Am Board Fam Med. 2010;23(2):195-203.

23. Lee SY, Stucky B, Lee J, Rozier RG, Bender D. Short assessment of health literacy - Spanish and English: a comparable test of health literacy for Spanish and English speakers. Health Serv Res. 2010;45(4):1105-21.

24. Welch V, VanGeest JB, Caskey R. Time, costs, and clinical utilization of screening for health literacy: a case study using the newest vital sign (NVS) instrument. J Am Board Fam Med. 2011;24(3):281-9.

25. Ryan J, Leguen F, Weiss B, Albury S, Jennings T, Velez F, et al. Will patients agree to have their literacy skills assessed in clinical practice? Health Educ Res. 2007;23(4):603-11.

26. VanGeest J. Welch, Weiner S. patients' perceptions of screening for health literacy: reactions to the newest vital sign. J Health Commun. 2010;15(4): 402-12.

27. Stagliano V, Wallace L. Brief health literacy screening items predict newest vital sign scores. J Am Board Fam Med. 2013;26(5):558-65.

28. Praska J, Kripalani S, Seright A, Jacobson T. Identifying and assisting lowliteracy patients with medication use: a survey of community pharmacies. Ann Pharmacother. 2005;39(9):1441-5.

29. Parikh NS, Parker RM, Nurss JR, Baker DW, Williams MV. Shame and health literacy: the unspoken connection. Patient Educ Couns. 1996;27(1):33-9.

30. Kountz D. Strategies for improving low health literacy. Post Grad Med J. 2009;121(5):171-7.

31. Bowen DJ. Steps for improving health literacy. The Clinical Advisor; 2016. p. $110-2$.

32. Rajda C, George N. The effect of education and literacy levels on health outcomes of the elderly. JNP. 2009;5(2):115-9.

33. Sheriden S, Halpern D, Viera A, Berkman N, Donahue K, Crotty K. Interventions for individuals with low health literacy: a systematic review. J Health Commun. 2011;16(3):30-54.

34. Schwartzberg J, Cowett A, VanGeest J, Wolf M. Communication techniques for patients with low health literacy: a survey of physicians, nurses, and pharmacists. Am J Health Behav. 2007:31(Sup 1):S96-S104.

35. The Newest Vital Sign. NY (NY): Pfizer; 2016 [cited 2016 May 19]. Available from: https:/www.pfizer.com/files/health/nvs_flipbook_english_final.pdf.

36. Weiss BD, Mays MZ, Martz W, Castro KM, DeWalt DA, Pignone MP, et al. Quick assessment of literacy in primary care: the newest vital sign. Ann Fam Med. 2005:3(6):514-22.

37. AHRQ. Health literacy universal precautions toolkit $2^{\text {nd }}$ Ed. Rockville: Agency for Healthcare Research and Quality; 2018. [cited 2019 June 19]. Available from: https:/www.ahrq.gov/professionals/quality-patient-safety/qualityresources/tools/iteracy-toolkit/index.html.

38. Shoemaker SJ, Staub-DeLong L, Wasserman M, Spranca M. Factors affecting adoption and implementation of AHRQ health literacy tools in pharmacies. Res Social Admin Pharm. 2013;9(5):553-63.

39. O'Neal KS, Crosby KM, Miller MJ, Murray KA, Condren ME. Assessing health literacy practices in a community pharmacy environment: experiences using the AHRQ pharmacy health literacy assessment tool. Res Social Admin Pharm. 2013:9(5):564-96.

\section{Publisher's Note}

Springer Nature remains neutral with regard to jurisdictional claims in published maps and institutional affiliations.

Ready to submit your research? Choose BMC and benefit from:

- fast, convenient online submission

- thorough peer review by experienced researchers in your field

- rapid publication on acceptance

- support for research data, including large and complex data types

- gold Open Access which fosters wider collaboration and increased citations

- maximum visibility for your research: over $100 \mathrm{M}$ website views per year

At $\mathrm{BMC}$, research is always in progress.

Learn more biomedcentral.com/submissions 